\title{
A resource allocation model to support efficient air quality management in South Africa
}

\author{
Urishanie Govender* Jan Kruger ${ }^{\dagger}$ \\ Received: 3 December 2008; Revised: 16 March 2009; Accepted: 13 May 2009
}

\begin{abstract}
Research into management interventions that create the required enabling environment for growth and development in South Africa are both timely and appropriate. In the research reported in this paper, the authors investigated the level of efficiency of the Air Quality Units within the three spheres of government viz. National, Provincial, and Local Departments of Environmental Management in South Africa, with the view to develop a resource allocation model. The inputs to the model were calculated from the actual man-hours spent on twelve selected activities relating to project management, knowledge management and change management. The outputs assessed were aligned to the requirements of the mandates of these Departments. Several models were explored using multiple regressions and stepwise techniques. The model that best explained the efficiency of the organisations from the input data was selected. Logistic regression analysis was identified as the most appropriate tool. This model is used to predict the required resources per Air Quality Unit in the different spheres of government in an attempt at supporting and empowering the air quality regime to achieve improved output efficiency.
\end{abstract}

Key words: Air quality, resource allocation model, project management, knowledge management, output efficiency, logistic regression.

\section{Introduction}

The South African government departments are widely praised for having the most innovative and progressive legislature, policies, and programmes in the world. However, a considerable gap was identified between written regulation and implementation into reality (Aladin, 2006). Efficient implementation of policies and strategies require that organisations allocate resources to activities that support project management, change management, and knowledge management practices (Rosacker, 2005; Batley, 2005).

A literature search on project management, change management and knowledge management practices in South African Government Departments revealed that these activities are

\footnotetext{
${ }^{*}$ Corresponding author: Graduate School of Business Leadership, University of South Africa, P.O. Box 392, Pretoria, 0003, South Africa, email: Urishanie.govender@ppc.co.za

${ }^{\dagger}$ Graduate School of Business Leadership, University of South Africa, P.O. Box 392, Pretoria, 0003, South Africa.
} 
not adequately addressed (Foti, 2005; Bridgman \& Davis, 2004; Rosacker, 2005). Streit and Guzman (1995) claimed that to be efficient, government departments must have a good understanding of the resources allocated to manage projects, deal with collaboration initiatives, address resistance to change and implement air quality management strategies. In their study, the term "resources" referred to peoples' time and the departments' budgets, which is similar to the approach in this study. Davenport and Marchand (2000) added that organisations which focus on knowledge management create an environment that facilitates the creation of knowledge, support the way people share and apply it, and improves the organisations' ability to manage change.

This paper deals specifically with the South African Air Quality Units within the national, provincial and local government departments; 228 units in total. The recent emphasis on air quality management was largely due to the increased awareness of the potential health impacts of air pollution, the lack of compliance action by government environment departments and the need for industries to rapidly change technology through efficient environmental authorisation processes (Pape, 2001). Regarding effective air quality management, Hadfield and Seaton (1999) identified gaps with respect to the lack of effective information management and developing knowledge systems to defend regulations on emissions for improved compliance actions.

Numerous air quality management challenges have been published on specific air quality management units in South Africa. One example is described in the work by Mokgoro (2000) who reported on the difficulty in implementing the National Department of Environmental Management's policies in the North West Provincial Department of Environment. These challenges included:

- Lack of reliable data and information to make informed decisions;

- An inadequate information management system; and

- National policies were imposed on the Department without regard to the capacity of the North West Province and other specific circumstances.

Foti (2005) supported the work of Mokgoro (2000) and added that the lack of continuity and sustainable decision support tools were the greatest weakness in the adoption of project management practices by provincial and local environment departments. Riege and Lindsay (2006) confirmed that knowledge management played a key role within public service, but stated that there was limited research and few guidelines on how governments can develop more effective knowledge management and public policy partnerships with stakeholders.

The Air Quality Units were also experiencing several challenges in terms of improving communication across the different spheres, accessing air quality information, and using the information to support the decision making required for effective management of air quality in the country (Lukey, 2007). Therefore, it was opportune to evaluate the potential for improving the output efficiency in this sector by evaluating their resource allocation trends to activities relating to project management, knowledge management and change management.

The aim of the work reported in this paper is to fit a resources allocation model that contributes towards the prediction of the output efficiency of the Air Quality Units, which 
may support efficient planning and budgeting. This raised the following question, investigated in this paper: To what extent can the South African Air Quality Units' efficiency be explained by the percentage of the resources allocated to indicators relating to project management, knowledge management and change management?

The term "resource allocation" refers to the apportioning of the officials' man-hour costs into activities relating to project management, change management and knowledge management. The "efficiency" of the units refers to the percentage completion of the mandated outputs, activities and strategic projects (where $100 \%$ efficiency implies that all required activities are completed).

\section{Measuring public sector efficiency}

Webster and Omar (2003) state that efficiency relates to the comparison between the inputs and outputs of an organisation. The measurement of efficiency generally requires (a) an estimation of input variables, (b) an estimation of output variables, and (c) a comparison between the two. At a given input, the greater the output, the more efficient an activity or organisation is (Webster \& Omar 2003).

Organisations use models as important tools for analysing businesses and developing strategies to improve efficiency (Recklies, 2004). Existing models for measuring efficiency suffer from limitations in the sense that the focus is primarily on improving product delivery time and requires the use of vast volumes of data that are not readily available in the public sector (Durant-Law, 2008). The model fitted in this study focuses on data that are captured as part of the public sector budget and performance reporting systems.

An efficient public service is one that undertakes its functions in the best possible and least wasteful manner (Webster \& Omar, 2003). In the absence of market force incentives, public service departments must utilise their resources optimally to carry out their mandate (Webster \& Omar, 2003). This emphasises the need for the Air Quality Units in order to understand the efficient allocation of their resources.

\section{The input variables of the Air Quality Units}

The studies published by previous researchers in the field of project management, knowledge management and change management that were reviewed in order to identify the activities to monitor as input variables into the model are summarised in Tables 7 in Appendix A. The man hours spent managing knowledge and knowledge processes, for example, was an important indicator used by Rwelamila (2007) in his work on understanding project management competence in public sector infrastructure organisations. He also argued that the public sector must allocate resources to formulating work processes, role descriptions, and databases of products or services to deliver efficiently on their routine activities.

Shenhar (2004) stressed the need for allocating resources to the implementation of strategic plans to support improved organisational efficiency. Crawford et al. (2003) also assessed 
activities relating to project management. They agreed that project management had the potential to improve the efficiency of government services if resources were allocated to managing the outsourcing of projects. Bridgman and Davis (2004) asserted that the better the knowledge base upon which public policies was built, the more likely the public sector departments were to succeed in implementing the policies. Their study focused on allocating resources to knowledge transferred within government, and prioritising and addressing system failures. Longman and Mullins (2004) recommended that for an organisation to resourcefully manage change, it must capture the learnings in a "projects lessons learned event and report."

The activities that were monitored in the different studies, as summarised in Tables 7 in Appendix A, were used to inform the selection of the twelve input variables, as listed in Table 1. These input variables were further grouped, as shown in Appendix A, into five categories viz. project management, knowledge management, routine, other and change management with the aim of simplifying the model.

$X_{1}$ : Routine tasks as per job description

$X_{2}$ : Managing strategic project or projects

$X_{3}$ : Set up and maintain monitoring stations for managing air quality information

$X_{4}$ : Develop legislation and decision support tools

$X_{5}$ : Document learnings and set up inhouse knowledge systems

$X_{6}$ : Communication with other Department

$X_{7}$ : Training and Development

$X_{8}$ : Manage Outsourcing as per business plans i.e. managing consultants and contracts

$X_{9}$ : Prioritising and addressing system failures

$X_{10}$ : Partner with other organisations

$X_{11}$ : Manage knowledge (centralised reporting system, updating department performance indicators)

$X_{12}$ : Other inputs

Table 1: Input variables used in this study. Of these, $X_{2}, X_{6}, X_{7}, X_{8}$, and $X_{10}$ are project management input variables, $X_{3}, X_{9}$ and $X_{11}$ are knowledge management input variables, and $X_{4}$ and $X_{5}$ are change management input variables.

\section{The output variables of the Air Quality Departments}

The outputs used in the model were based on the mandates of Air Quality Units, detailed in the Air Quality Act of 2004, as follows:

- Timeous development and adoption of regulations under the Act (for example, ambient air quality standards, emission limits, guidelines for air quality monitoring, modelling and management);

- Capacity building of local, provincial and national government personnel in terms of provision of adequate training, support and resources;

- Development and effective implementation of coherent air quality management systems comprising current and comprehensive emissions inventories, cost-effective and well run monitoring networks, suitable air dispersion models; and

- Standardisation of monitoring methods, emissions inventories, modelling approaches and source, emissions, air quality and meteorological data reporting. 
The resulting fifteen output variables are shown in Table 2.

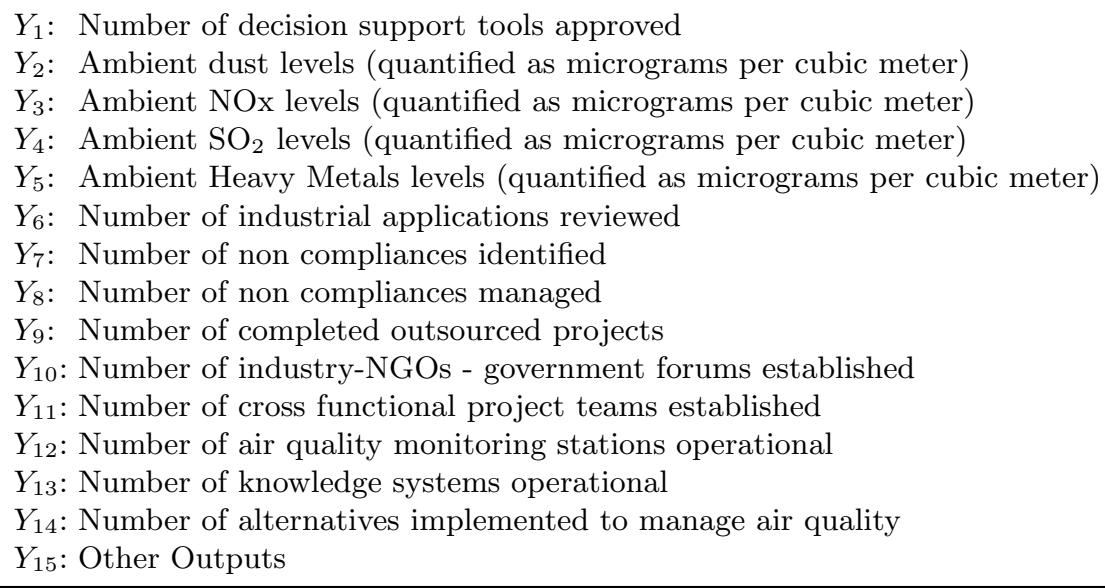

Table 2: Output variables used in this study (Air Quality Act, 2004).

\section{Methodology}

The research methodology focused on developing a regression model that could predict the efficiency of the Air Quality Units, based on the actual data collected for the period of two financial years $(2005 / 06$ and 2006/07).

The officials that were responsible for managing air quality in the South African National, Provincial and Local Environmental Departments were approached for the information relating to the identified inputs and outputs. Based on actual work hours, the officials estimated their man-hours spent on the input variables. The man-hour data set from the Air Quality Units was converted into man-hour costs, using the hourly compensation rates of the responsible individuals. The man-hour cost data set was then expressed as a percentage of the total available working hours in the year. The output information was extracted from the Air Quality Units' management reports. The number of completed items was expressed as a percentage of the total number of mandated activities. An extract of the input-output data set is shown in Appendix B. The respondents required that their information be maintained as confidential; therefore no further breakdown of the responses is included.

The data were validated and corrected for missing cells and possible incorrect entries. An exploratory analysis of the data was undertaken, followed by data preparation and grouping into categories. Preliminary assessment of the data was undertaken to test whether the data are amenable to linear regression. Violations in assumptions of normal distributions in the data set were identified which implied that linear regression analyses were not appropriate. Subsequently, the logistic regression technique was applied, as its application is not limited to many of the restrictive assumptions of linear regression models and is suitable for use with categorical data (Garson, 2008).

The input and output variables were subject to recoding of the original scores to ensure 
suitability of analysis, as recommended by Pallant (2005). A summary of the recoded variables used for the modelling process is shown in Table 3. SPSS (Statistical Package for the Social Sciences) [43] was used to fit the "best" logistic regression model.

\begin{tabular}{lll}
\hline Variables & Type & $\begin{array}{l}\text { Categories } \\
\text { and values }\end{array}$ \\
\hline Routine & Continuous/Independent & $0-100 \%$ \\
\hline Change Management & Recoded/Categorical data/Independent & $\begin{array}{l}2 \text { categories: } \\
0:<1.5 \% \\
1: \geq 1.5 \%\end{array}$ \\
\hline Knowledge Management & Recoded/Categorical data/Independent & 3 categories: \\
& & $0:<10 \% ;$ \\
& & $1: 10-20 \% ;$ \\
& & $2:>20 \%$ \\
\hline Project Management & Continuous/Independent & $0-100 \%$ \\
\hline Other & Continuous/Independent & $0-100 \%$ \\
\hline Output Efficiency & Recoded/Categorical data/Dependent & 2 categories: \\
& & $0: 10-50 \% ;$ \\
& & $1: \geq 50 \%$ \\
\hline
\end{tabular}

Table 3: Summary of the categories of the variables used to fit the model.

Cross validation of the logistic regression model was performed to overcome the problems relating to over fitting the model to noise in the data, generally experienced in using stepwise methods, by fitting the model to the data collected for the 2006/07 financial year. The 2006/07 data were also used to test the robustness of the model.

The logistic regression curve was developed to predict the probability of the outputs of the model, when the variables of interest were changed in terms of man hours allocated.

\section{Results}

The response rate from the air quality officials approached for information that was required to the fit the model was $100 \%$. The model fitted, using logistic regression, is shown in Table 4. The model allows for predicting the classification of the Air Quality Units as either less than $50 \%$ or greater than and equal to $50 \%$ efficient. The resource allocation model fitted is able to correctly predict, with a high degree of accuracy (89\%), the efficiency category of the Air Quality Units. Both data sets predominantly satisfied the statistical requirements for a significant model, which indicates the robust character of the model.

The two variables, resources allocated to other activities and the category allocation for knowledge management i.e. between 10-20\% of resources allocated to knowledge management are the only two inputs which contribute to the prediction of the Air Quality Units' output efficiency. This implies that between 10-20\% of the man-hours available in the Air Quality Units must be used to undertake activities relating to knowledge management. 
The positive and negative values in the models indicate the direction of the change (i.e. allocating resources to other activities would result in a decrease in output efficiency, while allocating between $10-20 \%$ of the resources on knowledge management would result in an increase in efficiency).

The chi-square goodness-of-fit test performed (see Table 5) indicated that the inclusion of the variables was justified, as the significance of the steps was less than 0.05 . This implies that there is adequate fit of the data to the model, meaning that at least one of the predictors is significantly related to the response variable.

\begin{tabular}{l}
\hline \multicolumn{1}{c}{$2005 / 06$} \\
\hline P(output $50 \%$ or higher $)=\frac{1}{1+e^{-z}}$ \\
where \\
$z=2.556-0.063$ other \\
$\quad+0.631 \mathrm{KM}$ (if $>20 \%$ man hours) \\
$\quad+4.372 \mathrm{KM}$ (if $10-20 \%$ man hours) \\
\hline
\end{tabular}

\begin{tabular}{l}
\hline \multicolumn{1}{c}{$2006 / 07$} \\
\hline $\mathrm{P}($ output $50 \%$ or higher $)=\frac{1}{1+e^{-z}}$ \\
where \\
$z=2.0473-0.062$ other \\
$\quad+0.64 \mathrm{KM}$ (if $>20 \%$ man hours) \\
$\quad+4.372 \mathrm{KM}$ (if $10-20 \%$ man hours) \\
\hline
\end{tabular}

Table 4: The logistic representation models for the 2005/06 and 2006/07 data sets.

\begin{tabular}{cclccc}
\hline Year & & & \multicolumn{3}{c}{ Degrees of } \\
\hline $2005 / 06$ & Step 1 & Step & 49.974 & 2 & 0.000 \\
& & Block & 49.974 & 2 & 0.000 \\
& & Model & 49.974 & 2 & 0.000 \\
& \multirow{2}{*}{ Step 2 } & Step & 23.411 & 1 & 0.000 \\
& & Block & 73.384 & 3 & 0.000 \\
& & Model & $\mathbf{7 3 . 3 8 4}$ & $\mathbf{3}$ & $\mathbf{0 . 0 0 0}$ \\
\hline \multirow{2}{2006/07}{} & \multirow{2}{*}{ Step 1 } & Step & 49.235 & 2 & 0.000 \\
& & Block & 49.235 & 2 & 0.000 \\
& & Model & 49.235 & 2 & 0.000 \\
& Step 2 & Step & 22.854 & 1 & 0.000 \\
& & Block & 72.089 & 3 & 0.000 \\
& & Model & $\mathbf{7 2 . 0 8 9}$ & $\mathbf{3}$ & $\mathbf{0 . 0 0 0}$ \\
\hline
\end{tabular}

Table 5: Chi-square goodness-of-fit test for the resource allocation model for the South African Air Quality Units. P: Estimated probability for Air Quality Units; KM: Knowledge Management.

\section{Discussion}

The model fitted showed that the Air Quality Units must allocate 10-20\% of their resources to managing knowledge in order to be more than $50 \%$ efficient. The individual activities that must be prioritised, as shown in Appendix A, are as follows:

- Manage air quality information from monitoring stations:

- Validate the air quality data,

- Inspect monitoring stations,

- Generate air quality reports with trends. 
- Prioritise and address system failures:

- Prioritise outputs based on planned goals,

- Document system failures and solutions,

- Establish monitoring and evaluation programmes,

- Review systems failures.

- Manage knowledge and knowledge processes:

- Set up knowledge systems,

- Have centralised reporting systems, performance indicator systems and project tracking systems.

In addition, the Air Quality Units must limit the resources allocated to managing other activities. These activities include:

- Reviewing housing development impact studies,

- Addressing public nuisance complaints,

- Supporting the development of local air quality bye-laws that were not related to air quality management (for example, bye-laws relating to managing informal settlements and traffic offenders),

- Managing projects that were not related to air quality management (for example, solid waste disposal site guidelines and land use management planning).

\section{Conclusion and way forward}

The resource allocation model is able to predict, with a high degree of accuracy, the output efficiency of the Air Quality Units based on actual resources allocated to project management, change management and knowledge management. This provides a firm guideline for Air Quality Units in South Africa to increase their output efficiency and ultimately improve air quality.

The work done with the Air Quality Units also showed that efficiency could be encouraged through the following activities:

1. Greater understanding of the definition of performance efficiency in terms of using the desired outputs to define the allocation of resources to inputs and working towards planned targets;

2. Securing commitment from top management to operate as a project management learning organisation and developing and sustaining interdisciplinary project teams both within the departments and across the different spheres;

3. Coordinating effort and exchanging technical information among different departments, industry sectors and non-government organisations to establish a comprehensive air quality knowledge system;

4. Emphasising the need within departments to prioritise and address system failures and share lessons learnt within the entire air quality regime;

5. Increasing the focus on developing a "collective brain" within government through an improved learning network system that would support the planned change in policies, institutional arrangement and behaviours within the air quality regime; 
6. Allocating 10-20\% of resources to knowledge management activities; and

7. Clearly defining the "Other tasks" that must be undertaken and minimising the resources allocated to these tasks.

An output of this study is that more is known about the concept of public sector output efficiency, its different interpretations and the relationship between knowledge management and output efficiency in the South African public sector. Future research work must focus on quantifying the minimum resources that must be allocated to the other activities performed by the Air Quality Units, which are over and above their mandates, to establish optimal resource allocation requirements for maximum output efficiency.

\section{References}

[1] BlaIr GM, 2001, Starting to manage the essential skills, Free Press, London.

[2] Air Quality Act, 2004, South Africa, [Statute], Government Gazette, 476, Pretoria, pp. 121-122.

[3] Aladin S, 2006, Research on local government in South Africa, Paper presented at the proceedings of the Aladin-Savusa Conference on South African Municipalities, Amsterdam.

[4] Batley R, 2005, The politics of service delivery reform, Palgrave, New York (NY).

[5] Bridgman P \& Davis G, 2004, The Australian policy handbook, $3^{\text {rd }}$ Edition, Allen \& Unwin Limited, Sydney.

[6] Celand DI, 1999, Project management: Strategic design and implementation, $3^{\text {rd }}$ Edition, McGrawHill, New York (NY).

[7] Davenport TH \& Marchand DA, 2000, Mastering information management, Prentice Hall, London.

[8] Durant-Law G, 2008, Knowledge matters [Online], [Cited September $6^{\text {th }}$, 2008], Available from: http://www.durantlaw.info/category.htm.

[9] Dvir D, Lipovetsky S, Shenha, AJ \& Tishler A, 1998, In search of project classification: A non-universal approach to project success, Research Policy, 27, pp 915-935.

[10] Englund R, Graham R \& Dinsmore P, 2003, Creating the project office: A manager's guide to leading organisational change, Jossey-Bass, San Francisco (CA).

[11] Foті R, 2005, Project management for public service, Project Management Network, 17, pp. 15-18.

[12] Frame JD, 2002, The new project management: Tools for an age of rapid change, complexity and other business realities, Jossey-Bass, San Francisco (CA).

[13] Garson DG, 2008, Logistic regression, [Online], [Cited August 22 ${ }^{\text {nd }}$, 2008], Available from: http://www. chass.ncsu. edu/garson/PA756/PA765syl.thm.

[14] Gray CF \& Larson EW, 2000, Project management: The managerial process, Irwin McGraw-Hill, Boston (MA).

[15] Grimshaw D, Vincent S \& Willmont H, 2002, Going private: Partnering and outsourcing in the UK public service, Public Administration, 80, pp. 475-502.

[16] Herzog JP, 1991, People, the critical factor in managing change, Journal of Systems Management, 42, pp. 6-11.

[17] Jupp V \& Younger MP, 2004, A value model for the public sector, Journal Outlook, 1, pp. 15-20.

[18] Kakabadse A \& Kakabadse N, 2001, Outsourcing in the public services: A comparative analysis of practice, capability and impact, Public Administration and Development, 21, pp. 401-403.

[19] Kessels JWM, 2001, Learning in organisations: A corporate curriculum for the knowledge economy, Futures, 33, pp. 497-506.

[20] KRUPNICK AJ, 2008, Challenges to managing air pollution, Journal of Toxicology and Environmental Health, 71, pp. 13-23.

[21] Laufer A, Denker GR \& Shenhar AJ, 1996, Simultaneous management: The key to excellence in capital projects, International Journal of Project Management, 14, pp. 189-199. 
[22] Longman A \& Mullins J, 2004, Project management: Key tool for implementing strategy, Journal of Business Strategy, 25, pp. 54-60.

[23] Lukey P, 2008, Chief Air Quality Officer for Department of Environmental Affairs and Tourism, [Personal Communication], Contactable at plukey@deat.gov.za.

[24] Mankins MC \& Steele R, 2005, Turning great strategy into great performance, Harvard Business Review, 7, pp. 65-72.

[25] Manley TR, Shaw HW \& Manley RC, 2007, Project partnering: A medium for private and public sector collaboration, Engineering Management Journal, 19, pp. 3-11.

[26] McCourt B, 2005, Knowledge Manager for Gauteng Department of Agriculture, Conservation and Environment, [Personal communication], Contactable at bmmcourt@gauteng.gov.za.

[27] Mokgoro J, 2000, Provincial experience in managing national policies on the transformation of the public service, Public Administration and Development, 20, pp. 141-153.

[28] Moorcroft D, 2006, Realising RBC's new vision for employee communications, Strategic Communication Management, 10(6), pp. 30-33.

[29] Morrison JM, Brown CJ \& Smit EVDM, 2006, A supportive organisational culture for project management in matrix organisations: A theoretical perspective, South African Journal of Business Management, 37, pp. 39-54.

[30] Mrayyan B \& HAMDi MR, 2006, Management approaches to integrated solid waste in industrialised zones in Jordan: A case of Zarqa City, Waste Management, 26, pp. 195-205.

[31] Nonaka I \& TAKeuchi H, 1995, The knowledge creating company: How Japanese companies create the dynamics of innovation, Oxford University Press, Oxford.

[32] Pallant J, 2005, SPSS survival manual: A step by step guide to SPSS analysis, McGraw-Hill Companies, Sydney.

[33] PAPE J, 2001, A public sector alternative: Samwu's efforts, South African Labour Bulletin, 25, pp. $45-50$.

[34] Pinto JK \& Slevin DP, 1988, Critical success factors across the project, Project Management Journal, 19, pp. 67-75.

[35] Quassim K, 2005, Project Office Manager of Gauteng Provincial Government, [Personal Communication], Contactable at kquassim@gssc.gov.za.

[36] Recklies O, 2004, The manager: Management portal, Williams \& Wilkins, New York (NY).

[37] RiEge A \& Lindsay N, 2006, Knowledge management in the public sector: Stakeholder partnerships in the public policy development, Journal of Knowledge Management, 10, pp. 24-39.

[38] Rosacker KM, 2005, Managing information systems projects within state government: Factors critical for successful implementation, PhD dissertation, University of Nebraska, Lincoln (NE).

[39] Roseau MD, 1998, Successful project management, $3^{\text {rd }}$ Edition, John Wiley \& Sons, New York (NY).

[40] Rwelamila PD, 2007, Project management competence in public sector infrastructure organisation, Construction Management and Economics, 25, pp. 55-66.

[41] Sharon SD \& Prefontaine L, 2003, Understanding new models of collaboration for delivering government services, Communications of the Association of Computing Machinery, 46, pp. 40-42.

[42] Shenhar AJ, 2004, Strategic project leadership-toward a strategic approach to project management, Research \& Development Management, 34, pp. 569-578.

[43] SPSS FOR Windows, 2006, Version 15.0.1, SPSS Incorporated, Chicago (IL).

[44] Sterner T, 2003, Policy instruments for environmental and natural resource management, Resources for the Future, Washington (DC).

[45] Streit GE \& GUZMAN F, 1995, Mexico City air quality: Progress of an international collaborative project to define air quality management options, Atmospheric Environment, 30, pp. 723-733.

[46] Tatikonda MV \& Rosenthall S, 2000, Successful execution of product development projects: Balancing firmness and flexibility in the innovation process, Journal of Operations Management, 18, pp. 401-425.

[47] Thamhain HJ \& Wilemon D, 1987, Building high performing engineering project teams, IEEE Transactions on Engineering Management, 34, pp. 130-137. 
[48] Thompson AA \& Strictland AJ, 1996, Strategic management: Concepts and cases, Irwin, Chicago (IL).

[49] Webster E \& Omar R, 2003, Work restructuring in post-apartheid South Africa, Work and Occupations, 30, pp. 194-213.

[50] Wenzel P, 2007, Public-sector transformation in South Africa: Getting the basics right, Progress in Development Studies, 7, pp. 47-64.

[51] Zuber-Skerritt O, 2002, The learning organisation, Action Learning and Action Research Journal, 9, pp. 143-149.

\section{Appendix A}

This appendix contains a summary (in tabular form) of the studies previously published in the field of project management, knowledge management and change management and how these studies gave rise to the set of input variables to the logistic regression model described in the main body of the paper.

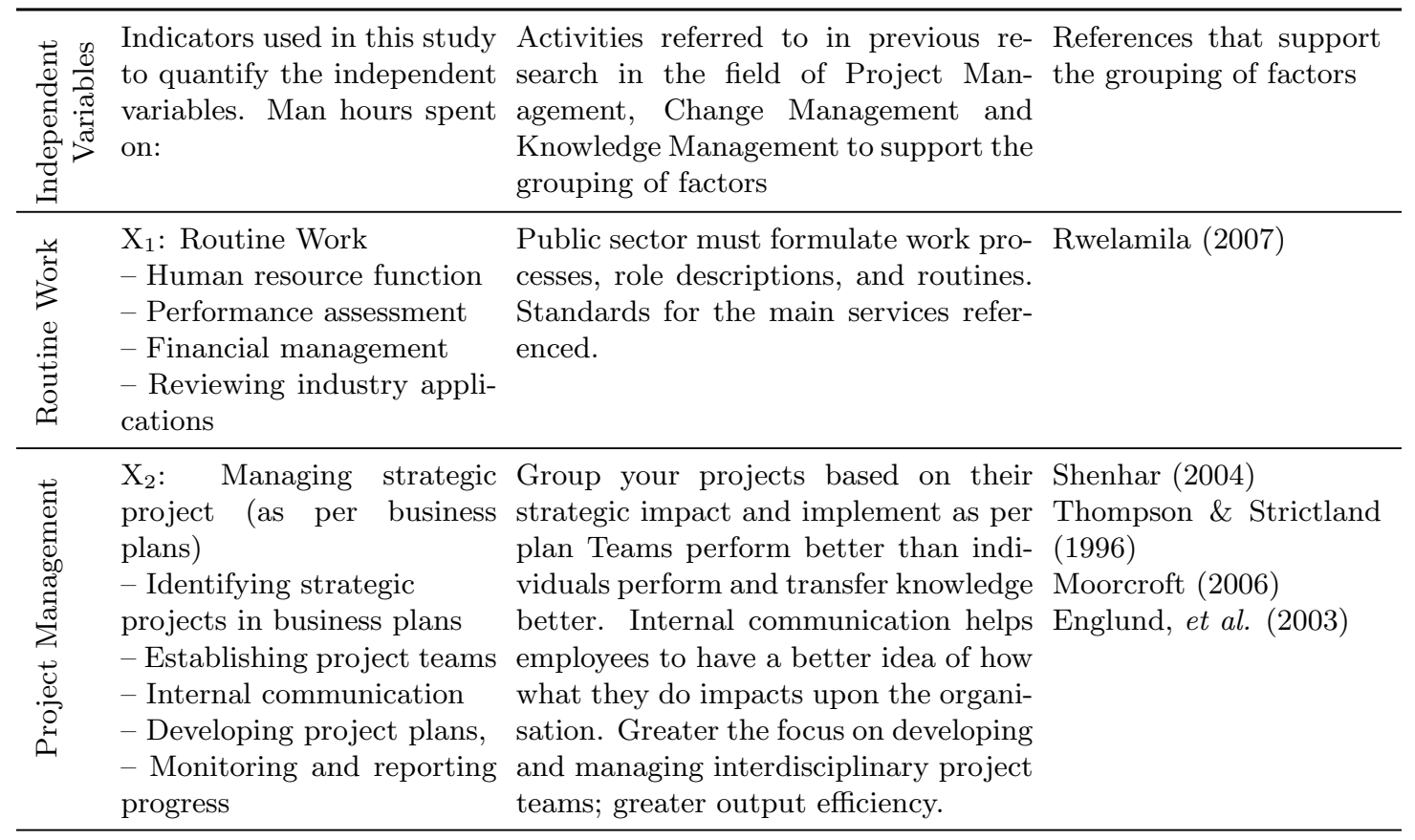




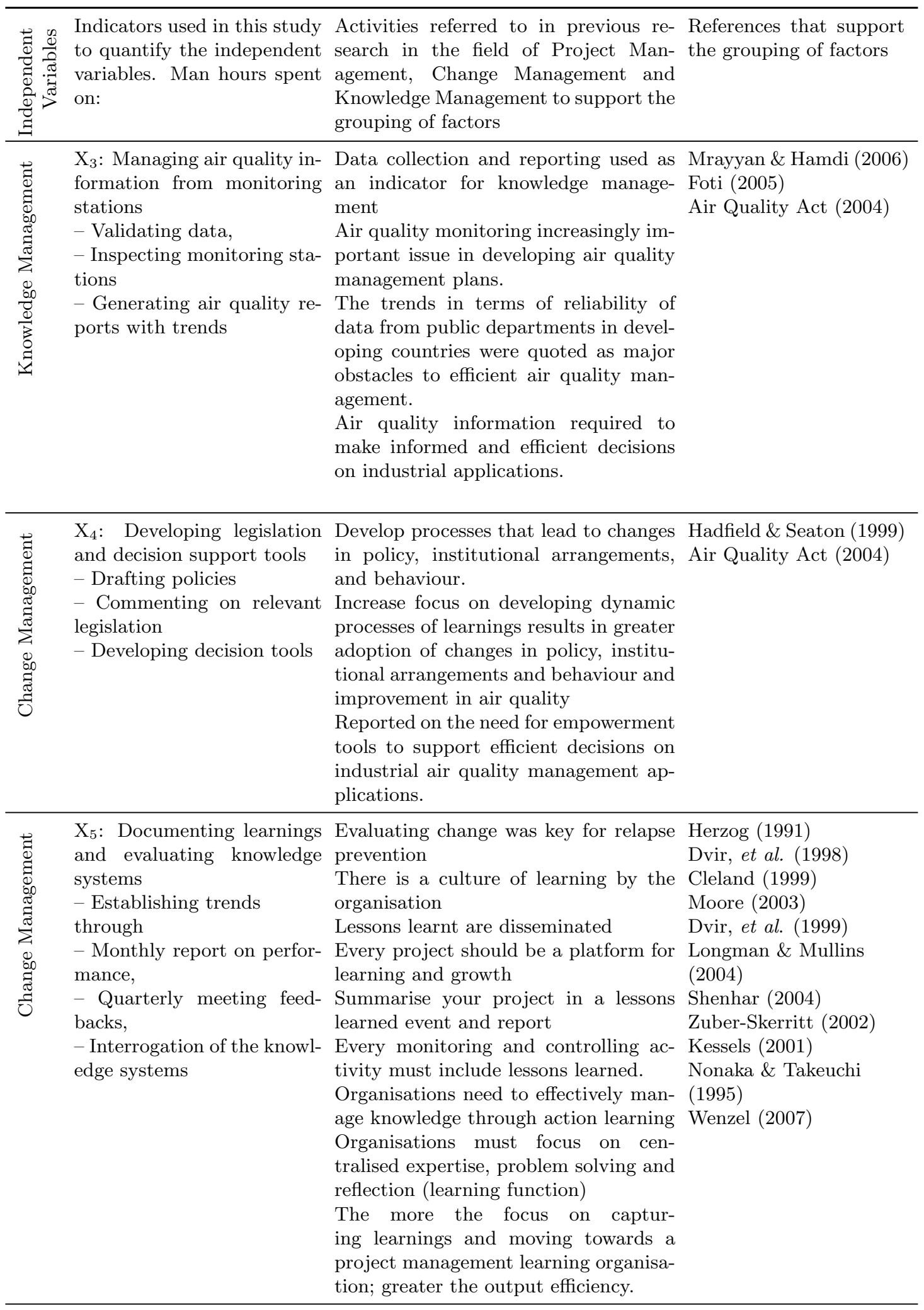




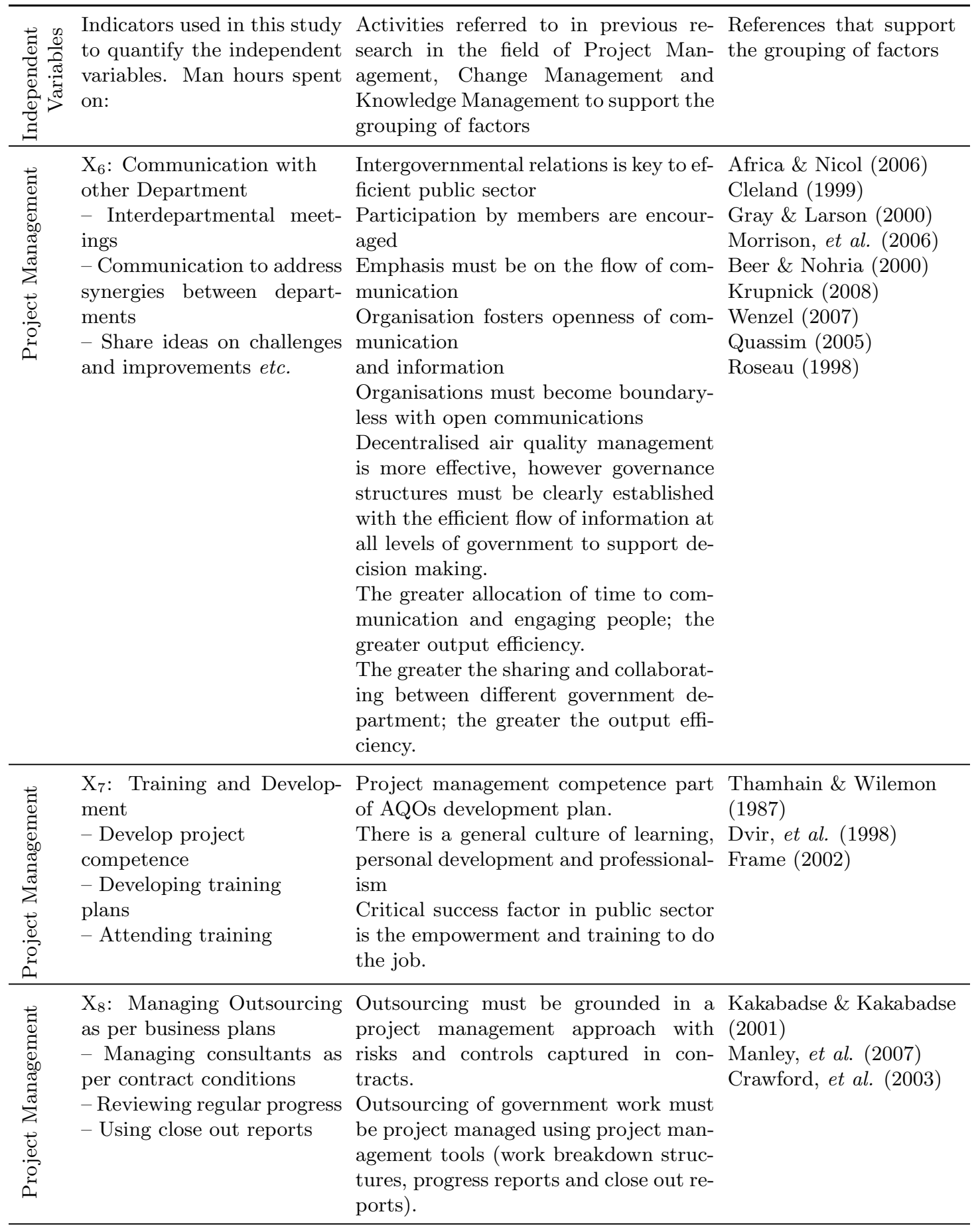




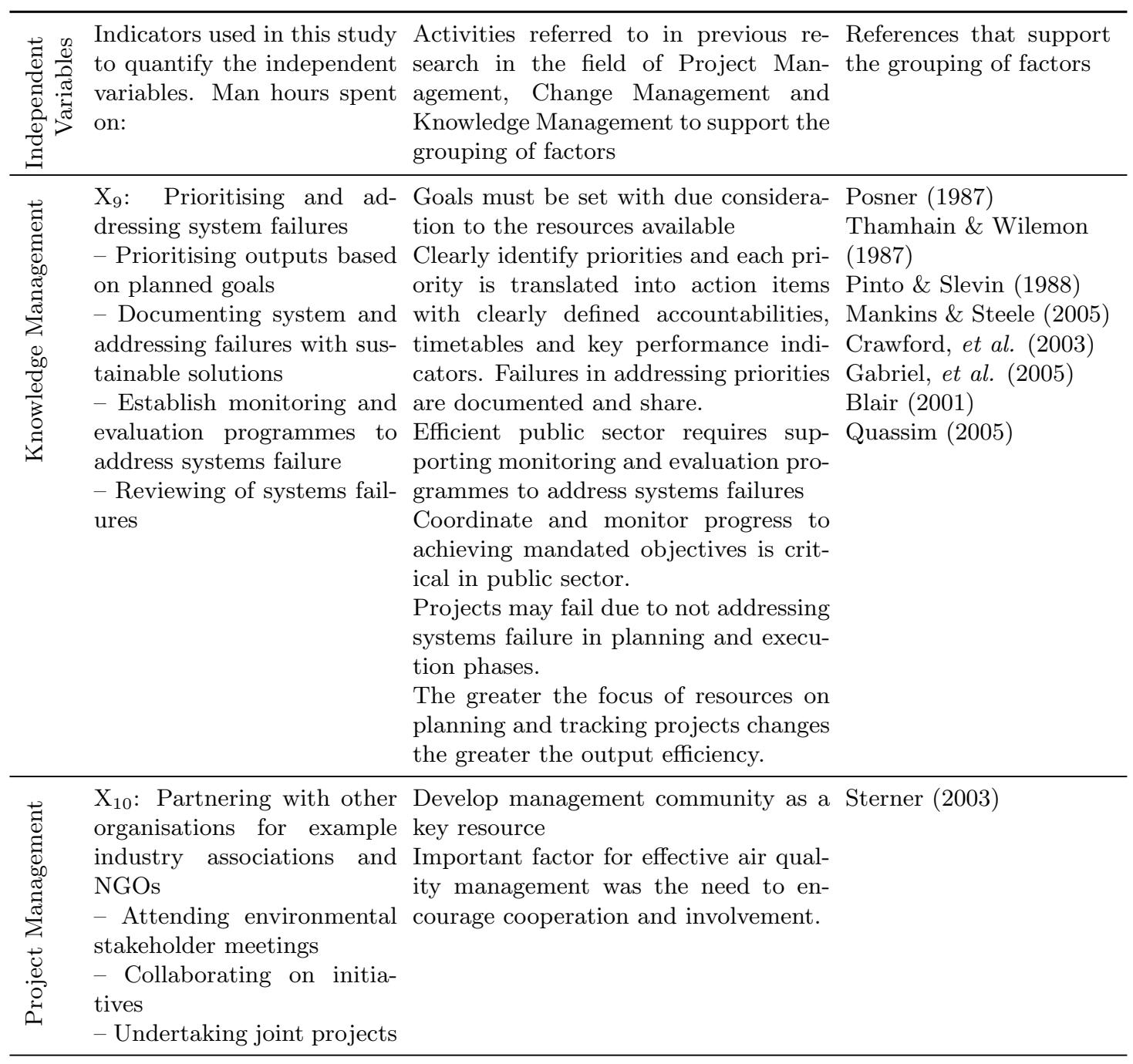




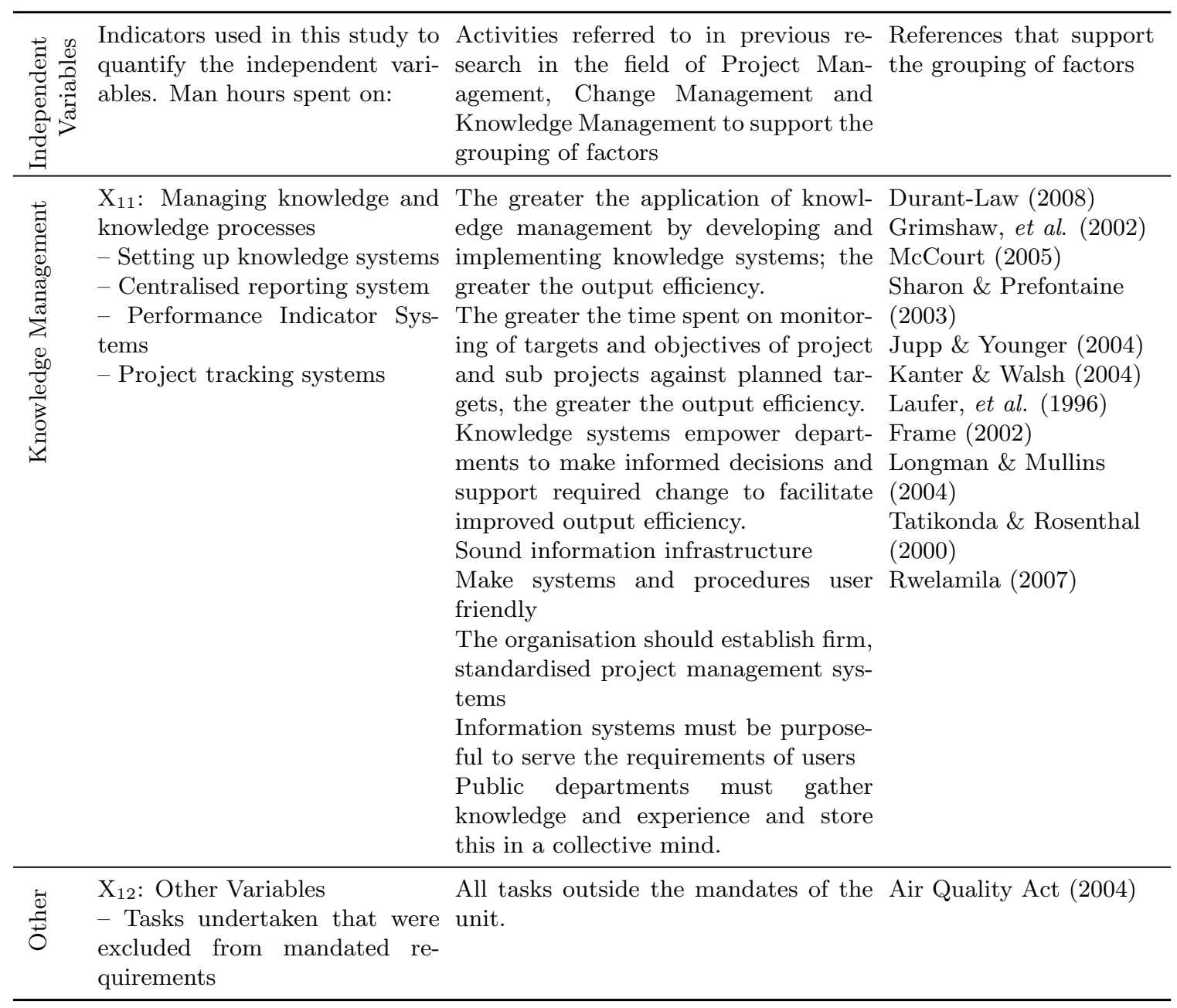

Table 6: Selection of the input variables from the literature review on project management, change management and knowledge management. 


\section{Appendix B}

This appendix contains a summary (in tabular form) of the input-output data set used to construct the logistic regression model described in the main body of the paper.

\begin{tabular}{|c|c|c|c|c|c|c|c|c|c|c|c|c|c|c|}
\hline 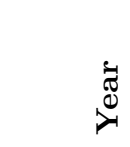 & $\overrightarrow{0}$ & 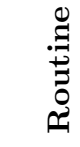 & $\sum_{a}$ & $\sum_{i}$ & $\sum_{0}^{1}$ & $\frac{\mathscr{d}}{\ddot{0}}$ & Z & $\stackrel{\circlearrowright}{\circlearrowright}$ & $\overrightarrow{0}$ & 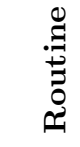 & $\sum_{a}$ & $\sum_{i}$ & $\sum_{U}$ & $\frac{\dot{d}}{\dot{0}}$ \\
\hline $2005 / 06$ & $100 \%$ & $21 \%$ & $48 \%$ & $13 \%$ & $12 \%$ & $6 \%$ & 1 & $2006 / 07$ & $100 \%$ & $20 \%$ & $51 \%$ & $12 \%$ & $15 \%$ & $2 \%$ \\
\hline $2005 / 06$ & $100 \%$ & $24 \%$ & $31 \%$ & $22 \%$ & $7 \%$ & $16 \%$ & 2 & $2006 / 07$ & $100 \%$ & $23 \%$ & $32 \%$ & $22 \%$ & $7 \%$ & $16 \%$ \\
\hline $2005 / 06$ & $93 \%$ & $32 \%$ & $43 \%$ & $11 \%$ & $10 \%$ & $3 \%$ & 3 & $2006 / 07$ & $93 \%$ & $33 \%$ & $37 \%$ & $13 \%$ & $10 \%$ & $8 \%$ \\
\hline $2005 / 06$ & $93 \%$ & $23 \%$ & $9 \%$ & $16 \%$ & $2 \%$ & $50 \%$ & 4 & $2006 / 07$ & $93 \%$ & $23 \%$ & $9 \%$ & $16 \%$ & $2 \%$ & $50 \%$ \\
\hline $2005 / 06$ & $93 \%$ & $32 \%$ & $43 \%$ & $11 \%$ & $10 \%$ & $3 \%$ & 5 & $2006 / 07$ & $93 \%$ & $33 \%$ & $43 \%$ & $11 \%$ & $11 \%$ & $2 \%$ \\
\hline $2005 / 06$ & $93 \%$ & $24 \%$ & $32 \%$ & $22 \%$ & $7 \%$ & $15 \%$ & 6 & $2006 / 07$ & $93 \%$ & $24 \%$ & $32 \%$ & $22 \%$ & $7 \%$ & $16 \%$ \\
\hline $2005 / 06$ & $93 \%$ & $31 \%$ & $31 \%$ & $21 \%$ & $12 \%$ & $5 \%$ & 7 & $2006 / 07$ & $93 \%$ & $27 \%$ & $31 \%$ & $23 \%$ & $10 \%$ & $9 \%$ \\
\hline $2005 / 06$ & $87 \%$ & $23 \%$ & $9 \%$ & $16 \%$ & $2 \%$ & $50 \%$ & 8 & $2006 / 07$ & $87 \%$ & $23 \%$ & $9 \%$ & $16 \%$ & $2 \%$ & $49 \%$ \\
\hline $2005 / 06$ & $87 \%$ & $24 \%$ & $31 \%$ & $22 \%$ & $7 \%$ & $15 \%$ & 9 & $2006 / 07$ & $87 \%$ & $24 \%$ & $31 \%$ & $22 \%$ & $7 \%$ & $15 \%$ \\
\hline $2005 / 06$ & $87 \%$ & $23 \%$ & $9 \%$ & $16 \%$ & $2 \%$ & $50 \%$ & 10 & $2006 / 07$ & $87 \%$ & $23 \%$ & $9 \%$ & $16 \%$ & $2 \%$ & $50 \%$ \\
\hline $2005 / 06$ & $87 \%$ & $32 \%$ & $43 \%$ & $11 \%$ & $10 \%$ & $3 \%$ & 11 & $2006 / 07$ & $87 \%$ & $32 \%$ & $43 \%$ & $11 \%$ & $10 \%$ & $3 \%$ \\
\hline $2005 / 06$ & $87 \%$ & $23 \%$ & $9 \%$ & $21 \%$ & $2 \%$ & $45 \%$ & 12 & $2006 / 07$ & $87 \%$ & $24 \%$ & $9 \%$ & $22 \%$ & $2 \%$ & $42 \%$ \\
\hline $2005 / 06$ & $80 \%$ & $2 \%$ & $1 \%$ & $1 \%$ & $0 \%$ & $96 \%$ & 13 & $2006 / 07$ & $80 \%$ & $2 \%$ & $1 \%$ & $1 \%$ & $0 \%$ & $96 \%$ \\
\hline $2005 / 06$ & $80 \%$ & $23 \%$ & $9 \%$ & $16 \%$ & $2 \%$ & $50 \%$ & 14 & $2006 / 07$ & $80 \%$ & $23 \%$ & $9 \%$ & $16 \%$ & $2 \%$ & $50 \%$ \\
\hline $2005 / 06$ & $20 \%$ & $2 \%$ & $21 \%$ & $23 \%$ & $1 \%$ & $52 \%$ & 89 & $2006 / 07$ & $20 \%$ & $3 \%$ & $21 \%$ & $24 \%$ & $1 \%$ & $52 \%$ \\
\hline $2005 / 06$ & $20 \%$ & $2 \%$ & $21 \%$ & $23 \%$ & $1 \%$ & $53 \%$ & 90 & $2006 / 07$ & $20 \%$ & $2 \%$ & $21 \%$ & $23 \%$ & $1 \%$ & $53 \%$ \\
\hline $2005 / 06$ & $20 \%$ & $2 \%$ & $21 \%$ & $23 \%$ & $1 \%$ & $53 \%$ & 91 & $2006 / 07$ & $20 \%$ & $2 \%$ & $21 \%$ & $23 \%$ & $1 \%$ & $53 \%$ \\
\hline $2005 / 06$ & $20 \%$ & $17 \%$ & $54 \%$ & $\%$ & $0 \%$ & $21 \%$ & 92 & $2006 / 07$ & $20 \%$ & $17 \%$ & $55 \%$ & $8 \%$ & $0 \%$ & $21 \%$ \\
\hline $2005 / 06$ & $13 \%$ & $3 \%$ & $2 \%$ & $0 \%$ & $0 \%$ & $94 \%$ & 102 & $2006 / 07$ & $13 \%$ & $4 \%$ & $2 \%$ & $0 \%$ & $0 \%$ & $94 \%$ \\
\hline $2005 / 06$ & $13 \%$ & $2 \%$ & $21 \%$ & $23 \%$ & $1 \%$ & $52 \%$ & 103 & $2006 / 07$ & $13 \%$ & $2 \%$ & $21 \%$ & $23 \%$ & $1 \%$ & $53 \%$ \\
\hline
\end{tabular}

Table 7: Extract of the input-output data set used to fit the resource allocation model. $N=$ Number of Samples; $K M=$ Knowledge Management; $C M=$ Change Management; $P M=$ Project Management; $y=$ output efficiency. 